\title{
Comparative analysis of information tendency and application features for projection mapping technologies at cultural heritage sites
}

Hengyi Li*i(1) and Hiromu Ito

\begin{abstract}
With the rapid development of interactive technologies using projection mapping (PJM), these digital technologies have introduced new interpretative possibilities for the presentation of cultural heritage sites. PJM attracts more visitors with greater expectations to cultural heritage sites through its excellent visual effects and guidance capabilities. In the past decade, especially after 2015, design events have frequently introduced digital projections to cultural heritage sightseeing spots worldwide. However, this trend has also led to the emergence of many digital projection events that merely exhibit beautiful projection effects on buildings and neglect to show the history and value of the cultural heritage site. Based on this phenomenon, this study compiled and analyzed 45 related cases of PJM applications at cultural heritage sites around the world from the past 5 years. These 45 examples were studied by disassembling the projection content, analyzing the information characteristics exhibited in each projection video, and arranging the obtained data on a timeline chart for analysis. According to the data, two information characteristics of PJM at cultural heritage sites can be observed: "the relationship between projection content and heritage" and "information tendency."The advantages and limitations of these characteristics were distinguished and suggestions for the application of PJM on cultural heritage sites were derived. These results can be used as a reference for other research studies on visitors to cultural heritage sites and improving digital interpretation and presentation designs.
\end{abstract}

Keywords: Cultural heritage sites, Projection mapping, Information tendency, Digital interpretation

\section{Introduction}

With the rapid development of projection mapping (PJM) and interactive technologies, these digital technologies bring new interpretative possibilities for the presentation of cultural heritage sites through their excellent visual effects and guidance capabilities, which give visitors more motivation and expectations when visiting these tourism spots. Hence, digital experiences are gradually becoming an important component of visitors' experiences at cultural heritage sites [1].

One of the critical missions in the international protection of cultural heritage sites is the interpretation of cultural heritage, which is an essential component in

*Correspondence: lihengyi233@126.com

University of Tsukuba, 1-1-1 Tennodai, Tsukuba, Ibaraki 305-8577, Japan the process of heritage conservation [2]. The methods for the use of cultural heritage sites are varied and have not been discussed fully. The planning designs for many cultural heritage sites separate the tourists from the environment and discourage their willingness to stay longer [3]. Considering this phenomenon, the value of using PJM for transmitting information about cultural heritage sites has been discussed around the world (Fig. 1). In 2018, the Japanese Ministry of Land, Infrastructure, Transport and Tourism produced guidelines to promote the implementation of PJM for "the purpose of regional development, promotion of tourism, promotion of community development, promotion of science, culture, art or sports, promotion of international mutual understanding, conservation of the global environment, sound development of young people and other public interests."
Springer Open

(c) The Author(s) 2021. Open Access This article is licensed under a Creative Commons Attribution 4.0 International License, which permits use, sharing, adaptation, distribution and reproduction in any medium or format, as long as you give appropriate credit to the original author(s) and the source, provide a link to the Creative Commons licence, and indicate if changes were made. The images or other third party material in this article are included in the article's Creative Commons licence, unless indicated otherwise in a credit line to the material. If material is not included in the article's Creative Commons licence and your intended use is not permitted by statutory regulation or exceeds the permitted use, you will need to obtain permission directly from the copyright holder. To view a copy of this licence, visit http://creativecommons.org/licenses/by/4.0/. The Creative Commons Public Domain Dedication waiver (http://creativecommons.org/publicdomain/zero/1.0/) applies to the data made available in this article, unless otherwise stated in a credit line to the data. 


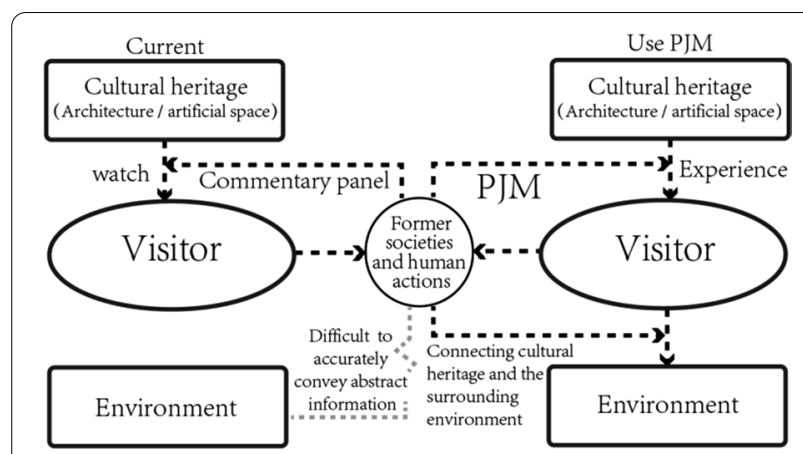

Fig. 1 Value of information transmission using PJM

[4] Guidelines for using PJM at public interest events have also been created in Tokyo.

Communicating the "outstanding universal value" of cultural heritage has been a top priority in the planning, design, and use of world heritage sites. Information about cultural heritage sites was previously conveyed through commentary panel discussions and models, which result in poorly updated information and viewing events that make it difficult to acquire information about the characteristics and histories of the cultural heritage sites [5]. Although virtual and augmented reality technologies can be used to address these issues, they remain limited to individual viewing uses [6, 7]. Conversely, PJM technologies can express a variety of information about the target cultural heritage site, which can be shared by multiple visitors [8]. PJM technologies also have good interactive features with visual appeal that can enhance guided tours and information delivery [9].

However, the examples of PJM technologies currently applied in cultural heritage sites around the world are mainly concentrated on art exhibitions. A considerable number of use projections only to produce visual effects or to redesign the cultural iconography [10]. The contents of these projections remain meaningful even when applied to modern buildings and landscapes, without the necessity of exhibiting them specifically at cultural heritage sites. These events use the reputation of the heritage site only for artistic or commercial purposes, while those traditional cultural elements that should be exhibited at the cultural heritage site (e.g., patterns, motifs, costumes, historical stories) are rarely addressed [11]. In addition, the only sightseeing experience that visitors can engage in is to see the cultural heritage site and it is difficult to argue that the information about the site's cultural heritage is well integrated within the environmental space, the information shown using PJM, and the visitors' experience [12].

This study found that PJM is important for the communication of cultural heritage sites' historical value.
The PJM technology has the ability to express substantial abstract information using projected images, which connect the visitors to the environment through their interactions with the images and the enrichment of the visitors' historical and participatory experience [13]. The PJM exhibition format makes it easier for the visitors to empathize with and emotionally connect to the environment at the cultural heritage site [14].

Based on this theory, this study aims to clarify the relationships between PJM and the cultural heritage sites. Two of the information characteristics for the use of PJM at cultural heritage sites could be summarized as "the relationship between projection content and heritage" and "information tendency." The advantages and limitations of PJM at cultural heritage sites were identified, with some concluding suggestions for the application of PJM at cultural heritage sites.

\section{Methods}

\section{Project organization and analysis}

Considering the large number of relevant PJM events in Japan and the fact that some events demonstrate traditional cultural elements related to the cultural heritage site of the event, this study mainly focuses on cases from Japan and presents analyses of more representative cases from around the world. Each reference case selected as an example must have a relatively complete video or image posted on the Internet. This study collated the opening hours, operating rules, messages conveyed, and equipment used for each example. The status of the event could be "on exhibit" or "closed."

\section{Technology classification and analysis of PJM video contents}

Two questions were analyzed to clarify the relationship between PJM and cultural heritage at cultural heritage sites: "which techniques are applicable to cultural heritage sites?" and "which techniques can be used to represent the historical culture of the cultural heritage site?"[15].

To obtain more systematic and reliable data, the differences and information characteristics exhibited by the PJM were analyzed from the two perspectives of "building surface PJM" and "medium-scale PJM." Moreover, the projection content was disassembled to analyze the information characteristics exhibited in each projection video. The resulting information was organized for analysis using an original timeline chart. Furthermore, through the comparative analysis of the data for the two information characteristics, the information tendency of PJM exhibited in cultural heritage sites was analyzed and suggestions for improvement were derived. 
To ensure the versatility and validity of the analysis, the original timeline chart was designed as a method for analyzing the PJM video content (Fig. 2). By dividing the PJM video content into multiple time periods, the number of scene units and the information trends in each period were analyzed and recorded. Each time node represents a scene transition and if the color is gray for a period, it means that no specific information was exhibited for that time period. The accumulation of two colors in a period indicates that multiple types of information were exhibited. In addition, the number recorded after the explanatory text is the number of scene units within that period.

\section{Results}

\section{Case sorting and classification}

This study formulates three selection criteria for cases worthy of analysis, that is, open projects within 5 years from 2020; open cultural heritage sites, including historical or cultural buildings and parks; and the PJM contents must be related to the history, events, status, and building functions of the cultural heritage site.

The example cases that meet criteria 1 and 2 were selected first. The purpose of this step was to gather as many research subjects related to the topic as possible. The case study produced a preliminary idea of which types of PJM were often used in cultural heritage sites and their characteristics. After the case collection, we used criterion 3 to determine the relationship between the PJM content and the cultural heritage site, and also determine whether the case exhibits information related to the site's cultural heritage, including history, patterns, clothing, characters, and other information (Table. S3). A case being marked as "unrelated" means that the content exhibited in the projection was not related to the heritage site's history and culture. A case being marked as "Less related" means that no more than $30 \%$ of content in the event was related to cultural heritage. For instance, among the four exhibition projects in the Kawa and Mori Light Art Festival held in Tokushima Central Park in
2018, only the indoor holographic projection was related to the local culture ( $25 \%$ related). The time and activity names of the example cases are shown in Additional file 1: Table S3 [16].

As complete images or video materials could not be obtained for some individual events at cultural heritage sites, this study used the heritage site as the unit and prioritized 45 heritage sites in the analysis.

According to the results of our analysis, the PJM contents for 25 cultural heritage sites were related to the heritage history and cultural elements at the target sites, accounting for $55.6 \%$ of the total. However, among 25 sites, some cases have very little relevance to the target cultural heritage and should be marked as "less related." For instance, just a few traditional Japanese paintings were exhibited in the example of Nijo Castle in Kyoto and the overall content borrows from cultural elements for exhibition as beautiful projections. When these examples were excluded, only 16 cases met the above three conditions, accounting for $35.6 \%$ of the total.

Example cases around the world were then analyzed to enumerate their PJM contents and interactive possibilities at the cultural heritage site (Table 1). The contents of PJM cases were more related to the heritage (about 60\% of the content is related to the heritage) or showed culture in a special way (e.g., Tokushima Central Park used a holographic projection to show its "Abo Dance" exhibition). These examples provide a reference for the analysis of information characteristics.

The representative cases in Japan were mostly concentrated in various shrines, ancient castles, and traditional gardens. Judging from the names of the example cases, they are more like "festivals" than events. In general, the Japanese examples are more like "light festivals" to commemorate the local history, culture, and customs. The projections in these light festivals were not limited to building surface PJM; many projections were used over the entire landscape. Moreover, the Japanese examples emphasize more the interactive experience between

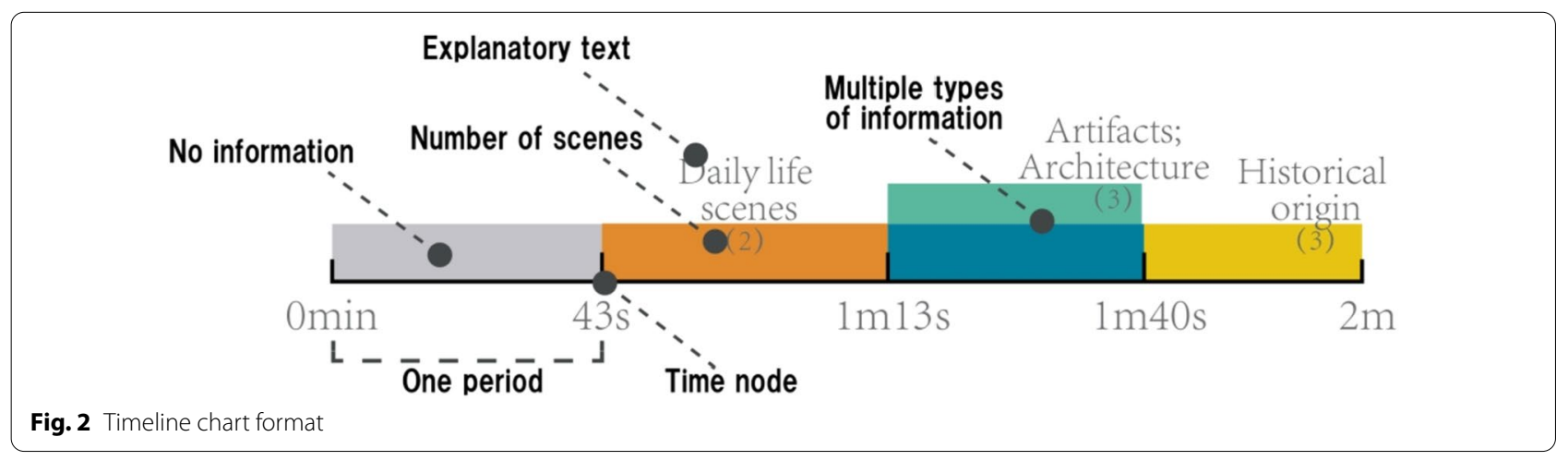




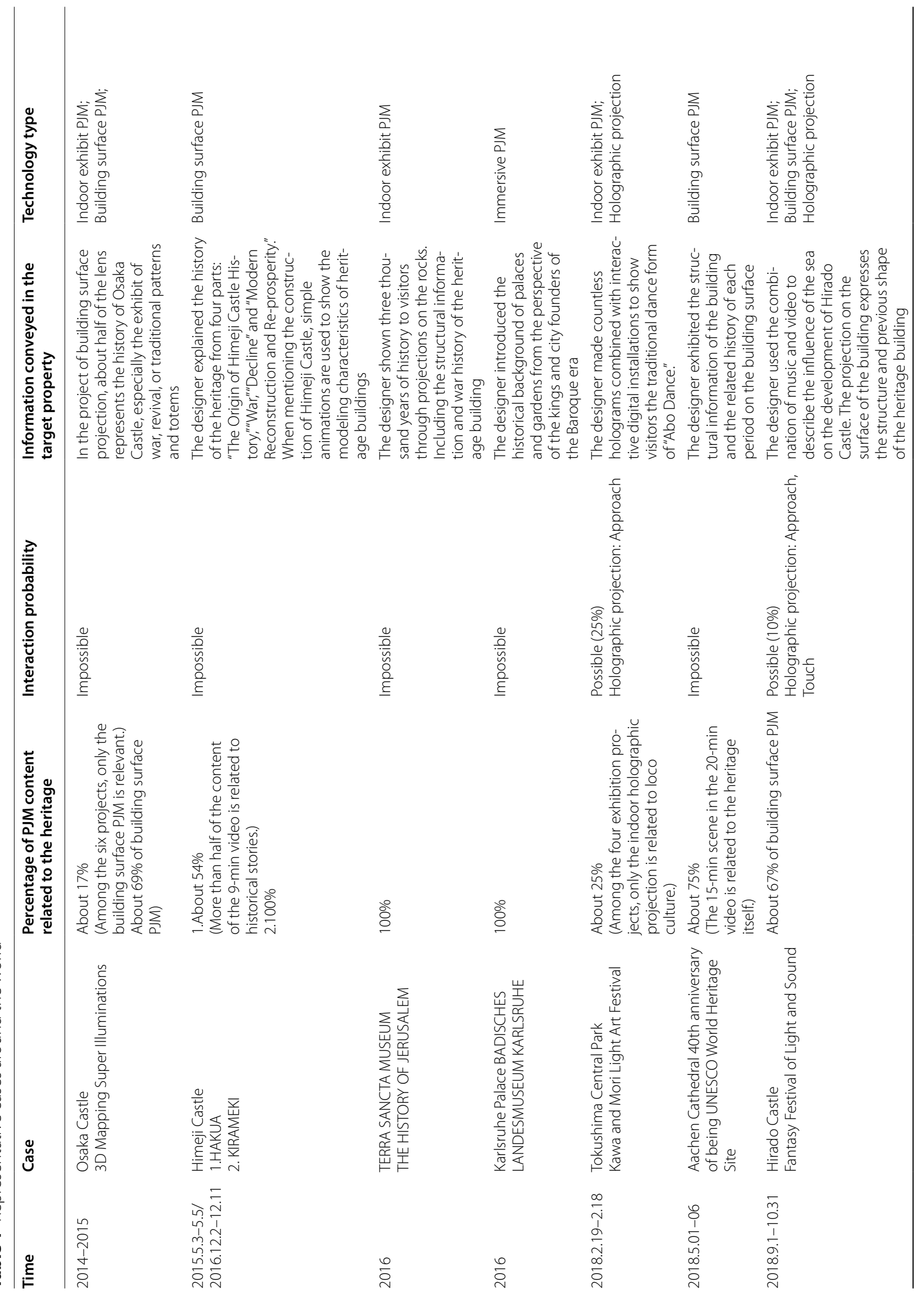




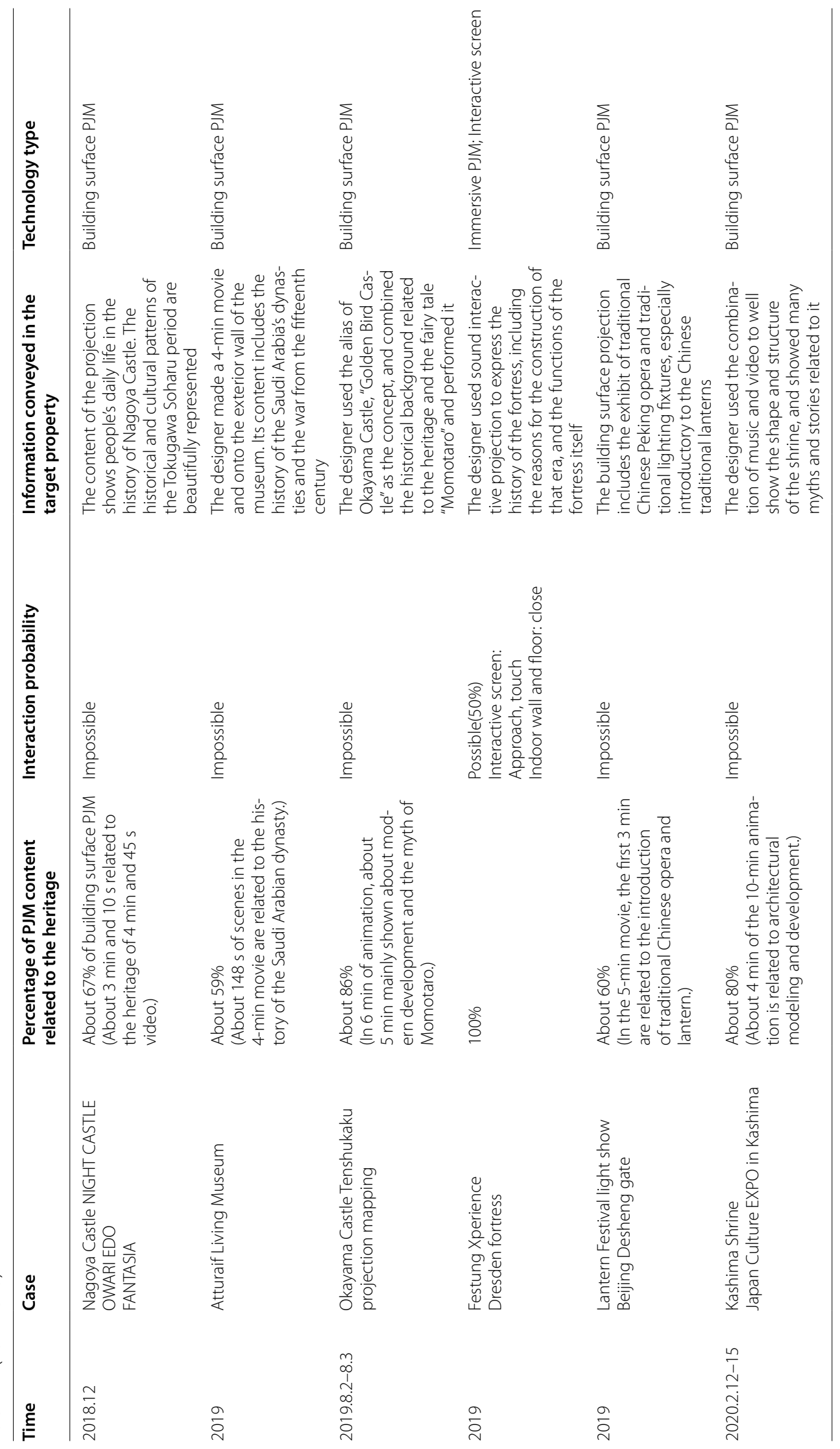


visitors and the environment than flashy projection exhibitions. These events in Japan are usually held every year at a fixed time, such as the historical events and folk festivals related to cultural heritage sites [17]. The event contents are basically the same as in the previous years, but with frequent thematic innovations and content revisions. In addition, there are cases where both permanent and festival-only programs are set up to allow the visitors to appreciate the PJM exhibition at the cultural heritage site at any time [18].

Accordingly, many similarities can be observed between the relevant example cases in China and Japan. Most Chinese examples focus on large historic buildings, bridges, and walls, among other structures with cultural heritage. Judging from the names of the events, these Chinese events are often described as a "festival light show," such as the light shows at the Lantern Festival and Dragon Boat Festival. The purpose of these festivals is to celebrate the local traditional culture and history. Although the duration of the projections at these events is short, the projection content is concise and traditional opera and artificial creations are often showcased. For instance, the stage, costumes, lanterns, and other elements of traditional Chinese Peking opera were exhibited in the light show during the Lantern Festival at Beijing's Desheng Gate in 2019.

The relevant European and American examples were mostly large-scale projection events onto church buildings and cultural walls. In terms of their projection content, these cases show more information about "war and historical development" and "architecture and urban structures." Taking as an example the "Festung Xperience" of Dresden fortress in Germany, the PJM designers projected a manuscript onto the architectural structure of Dresden Fortress to show visitors its structural features and functions in different periods. In particular, the projection in the main area shows the history of the Second World War and the crucial role played by Dresden Fortress in the war.

In addition, this study analyzed and identified the vehicles often used for PJM technologies at cultural heritage sites, including building surfaces, landscapes, and interiors. The building surfaces include castles, city walls, shrines, gates, museums, and churches, while landscapes include national parks, small city parks, and traditional courtyards [19]. In addition, the interior spaces of underground fortresses, castles and museums were also often used as vehicles for PJM technologies.

In addition to the above categories, PJM technologies are also used during some special occasions, such as on theaters and bridges for local history celebrations. Based on the above categories and the case names and times recorded in the timeline chart, it can be seen that PJM events at cultural heritage sites were more inclined to be light festivals and shows, where ornamental experiences prevail. These events are often accompanied by some commemorative festival or historical event, most of which have an open cycle. Thus, PJM events at cultural heritage sightseeing spots can also be classified into "short-term special events" and "daily programs" according to the visitors' needs. Among these events, daily programs are often combined with medium-scale PJM technology because the equipment placement is easier with more interactive functions.

\section{Information characteristics of building surface PJM}

Based on the summarized cases, this study analyzes seven related examples of building surface PJM (see Table 1): 3D Mapping Super Illuminations at Osaka Castle in 2015; Hakua at Himeji Castle in 2015; Night Castle Owari Edo Fantasia at Nagoya Castle in 2018; Atturaif Living Museum in Saudi Arabia in 2019; Fantasy Festival of Light and Sound at Hirado Castle in 2018; Tenshukaku projection mapping at Okayama Castle in 2019; and the 40th anniversary of being created an UNESCO World Heritage Site at Aachen Cathedral in 2018.

To distinguish the information characteristics of PJM on architectural surfaces, this study divided the above seven examples into two groups with reference to the PJM content and the length of projection: "historical introduction" and "thematic" cases. The average length of projection media in the "historical introduction" group was $10 \mathrm{~min}$ (10-min type), including the three cases at Osaka and Himeji castles and Aachen Cathedral. The average projection length in the "thematic" group was 5 min (5-min type), including the four examples at Atturaif Living Museum and the Hirado, Nagoya, and Okayama castles. Both groups used building surface PJM, but the exhibition logic for their projected contents differed.

This study classified the PJM information exhibited at heritage sites into four major categories and 12 corresponding subcategories (Fig. 3), including history-related (war history, historical daily life scenes, historical backgrounds and origins, historical figures), architecturerelated (structure and construction processes, historical appearances), folklore-related (mythical stories, folklore operas), and artifact-related (cultural relics, paintings and patterns, traditional costumes) subcategories, in addition to a subcategory for special effects animations without specific cultural heritage-related information. Moreover, the basis of these classifications emerged from the analysis of the video and picture data from all the events described in Table 2. Each type of information has a representative color. This study used the original timeline chart to analyze the contents of the PJM videos. Figure 2 explains the styles used in the timeline chart. 
As a large number of timeline charts were used in the analyses in this study, only the charts for the four most representative cases are shown (the other data are presented Additional file 1: Fig.S1) [20, 21].

The first category was the most common, that is, history introductions (Fig. 4). This type of projection typically takes a long time, about $10 \mathrm{~min}$ on average, with specific cases that last up to $20 \mathrm{~min}$. This type of projection is very rigorous in its presentation of the related historical story, with strict control over the chronological order of historical occurrences. For instance, in the 3D Mapping Super Illuminations at Osaka Castle in 2015 [22], the PJM designer showed the historical origin and development process of Osaka Castle through a 10-min video, especially the process of destruction and reconstruction. Similarly, in Hakua at Himeji Castle in 2015 [23], the PJM designer expounded the history of the building's cultural heritage in four parts exploring the origin of Himeji Castle, the war experience, short-term decline, and the building's modern reconstruction and return to prosperity. In addition, this type of projection tends to present a richer amount of information with a narrative explanation.

The second type of PJM is thematic cases (Fig. 5). For instance, in the Night Castle Owari Edo Fantasia at Nagoya Castle in 2018 [24], the projection shows people's daily life in historical scenes of Nagoya and cultural patterns from the Tokugawa-Soharu era. Similarly, in an exhibition at the Atturaif Living Museum in Saudi Arabia in 2019 [25], the design conception of the projection was to let the heritage building tell its own historical story. The PJM design team made a 4-min movie to show the history of the development of the Saudi Arabian dynasty. Compared with the 10-min example cases, this type of PJM is preferred to show the cultural characteristics of heritage sites using a specific theme.

This study classifies building surface PJM into two types based on the length of time: around $5 \mathrm{~min}$ (5-min type) and $10 \mathrm{~min}$ or more ( $\geq 10$-min type). The 5 -min type PJM is very thematic, with contents mostly focused on one or two types of information. They have an obvious "topicality" Conversely, the $\geq 10$-min type PJM is richer in information. This type of PJM strictly adheres to the timeline of historical stories, and many traditional Japanese decorative art motifs and totems are also shown. Therefore, it can be considered that the $\geq 10$-min type PJM has "comprehensive" and "narrative".

In addition, this study referred to the number of scene units recorded at the end of the explanatory text and produced a histogram (Fig. 6) to show the information characteristics of the building surface PJM. The comprehensive data includes all scene units for the seven cases. The data were used to categorize 11 types of information into three groups, that is, independent stories and scenes (marked as triangles), causal logic (marked as circles), and decorative patterns (marked as squares). Based on the distribution of the graphs, we can determine which types of data were exhibited more frequently and the information tendency of building surface PJM. According to the data, building surface PJM often exhibits causeand-effect rational information and continuous story information. In other words, the building surface PJM exhibits continuous information, such as stories of historical development and war histories, which is the major use pattern for building surface PJM.

\section{Information characteristics of medium-scale PJM}

The medium-scale PJM applied at cultural heritage sites mainly focuses on exhibit PJM, immersive PJM, and holographic projections. Each type of PJM technology can combine the interactive devices for the visitors' interactive experience. This study analyzes nine related examples of medium-scale PJM (see Table 1): Kirameki at Himeji Castle in 2016; the Lantern Festival light show at Beijing's Desheng Gate in 2019; Night Castle Owari Edo Fantasia at Nagoya Castle in 2018; the Fantasy Festival of Light and Sound at Hirado Castle in 2018; the Japan Culture Expo in Kashima at the Kashima Shrine Gate in 2020; the History of Jerusalem exhibition at Terra Sancta Museum in Jerusalem in 2016; the Festung Xperience at the Dresden Fortress in 2019; Badisches Landesmusium Karlsruhe at the Karlsruhe Palace in 2016; and the Kawa and Mori Light Art Festival held in Tokushima Central Park in 2018.

Because of the short exhibition time for most of these medium-scale PJM projects, this section only analyzes the contents of individual scenes and counted the number of scene units for each projection. The color classifications for this information are the same as that used for the building surface PJM project (see Additional file 1: Fig S2; Table S4 for the other data) [26-28].

The first representative case is Kirameki at Himeji Castle in 2016 (Table 2; Fig. 7) [29]. This case study includes not only five short exhibition projections, but also a long PJM of almost 8 min projected onto the castle wall surface. This is a representative example of outdoor medium-scale PJM, where the event is comprised of six small projections. The PJM designers tell the history of Himeji Castle by presenting six different independent historical stories. Each projection presents a short historical story and guides the visitors to the next projection in sequence.

The next representative case is the Festung Xperience at Dresden Fortress in 2019 (Table 3) [30]. This case is completely representative of a medium-scale interior PJM. The PJM designer created a series of small separate 


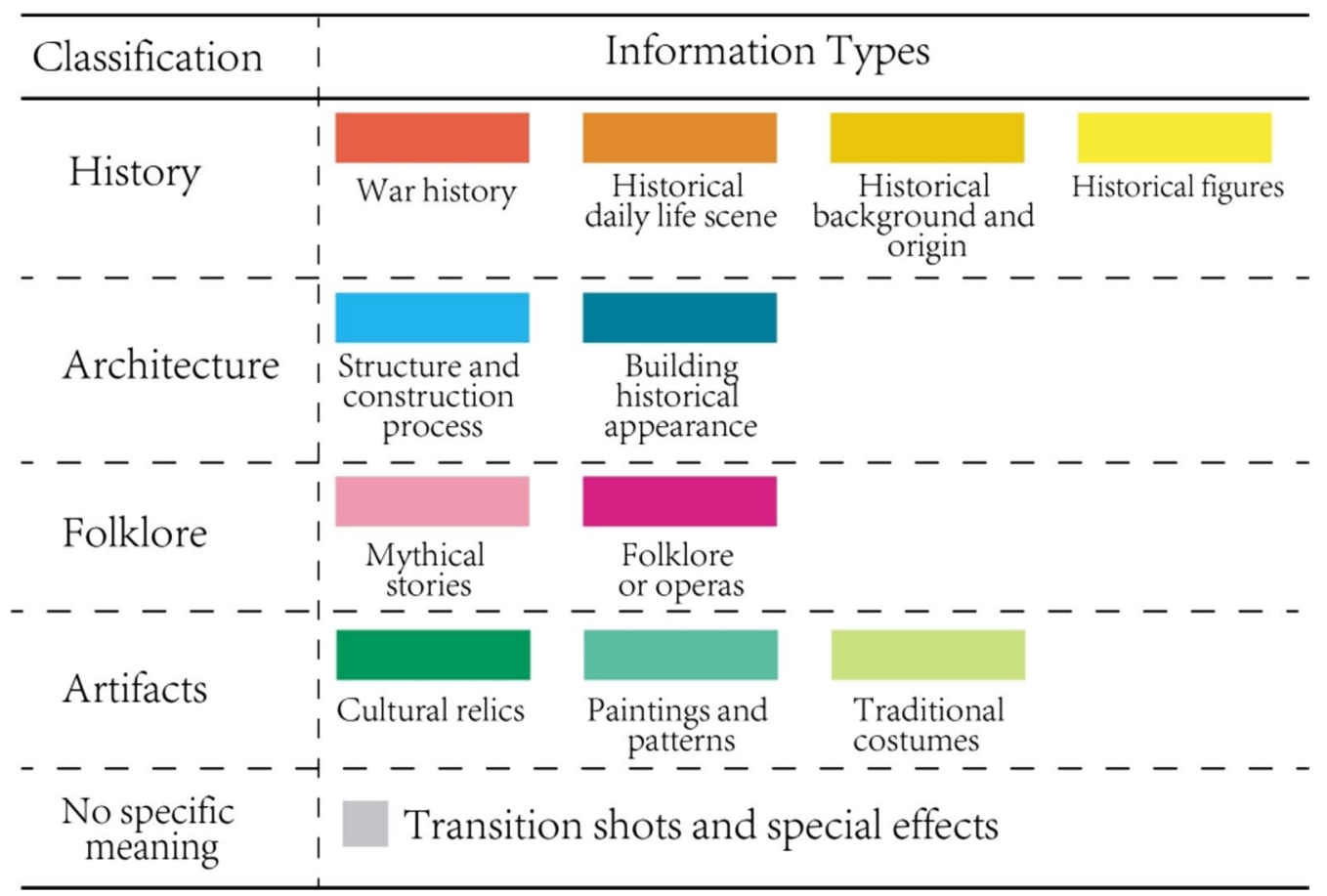

Fig. 3 Information classification and types

scenes to show the history of the Second World War and the shape of the structure associated with the fortress. Similarly to Kirameki, the presentation of the building's history was done through independent scenes and short stories. Moreover, the designer shows the function, spatial layout, and role of the fortress to the visitors using an interactive PJM that uses sound to interact with the visitors. In addition, the information about the cultural heritage site was divided into many independent scenes, such as scenes of people farming collectively, being prepared for war, or daily life in peacetime. In particular, the theater in the main arena shows the form and function of each area of the fort and their specific roles during the war years.

Next, we discuss the information tendency data as presented using a histogram (Fig. 8).

According to the data, medium-scale PJM has a high degree of generality and a relatively even variety of information. Similar to building surface PJM, medium-scale PJM also has excellent expressive capabilities for the exhibition of decorative elements such as totems and patterns. However, medium-scale PJM present less information about historical origins and development than the building surface PJM. That is, the quieter content of building service PJM does not show the complete historical timeline and process for the cultural heritage site, but rather the personal stories associated with important related historical figures.

\section{Discussion \\ Comparison of historical story exhibition logic}

In evaluating the differences in depicting historical stories between building surface and medium-scale PJM, we take Atturaif Living Museum and Kirameki as examples. Although both cases present the histories of their respective cultural heritage sites, the ideas and logic of the presentations differ. The logic of the historical presentation at Atturaif Living Museum begins with the origin of Saudi Arabia's royal family. The storyline is after the king was acknowledged by the Saudi Arabian people, he fought wars, achieved victories, and finally united the country. The PJM designer uses a continuous storyline to introduce this history. Conversely, the logic of Kirameki's historical introduction begins with the personal stories of important historical figures, which are clearly independent, but each story has some connection with the others and are related to the historical or cultural elements of Himeji Castle. Thus, we can judge that the medium-scale PJM always conveys information related to historical figures and artifacts because of the independence of the projected information. 


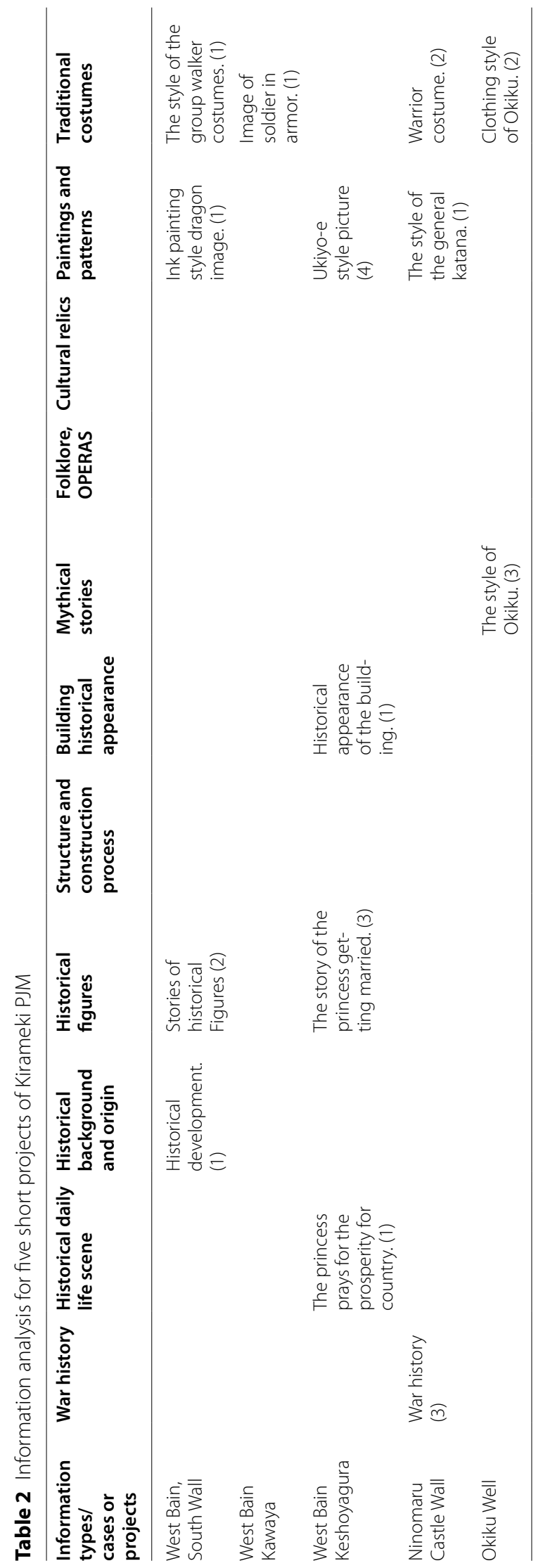



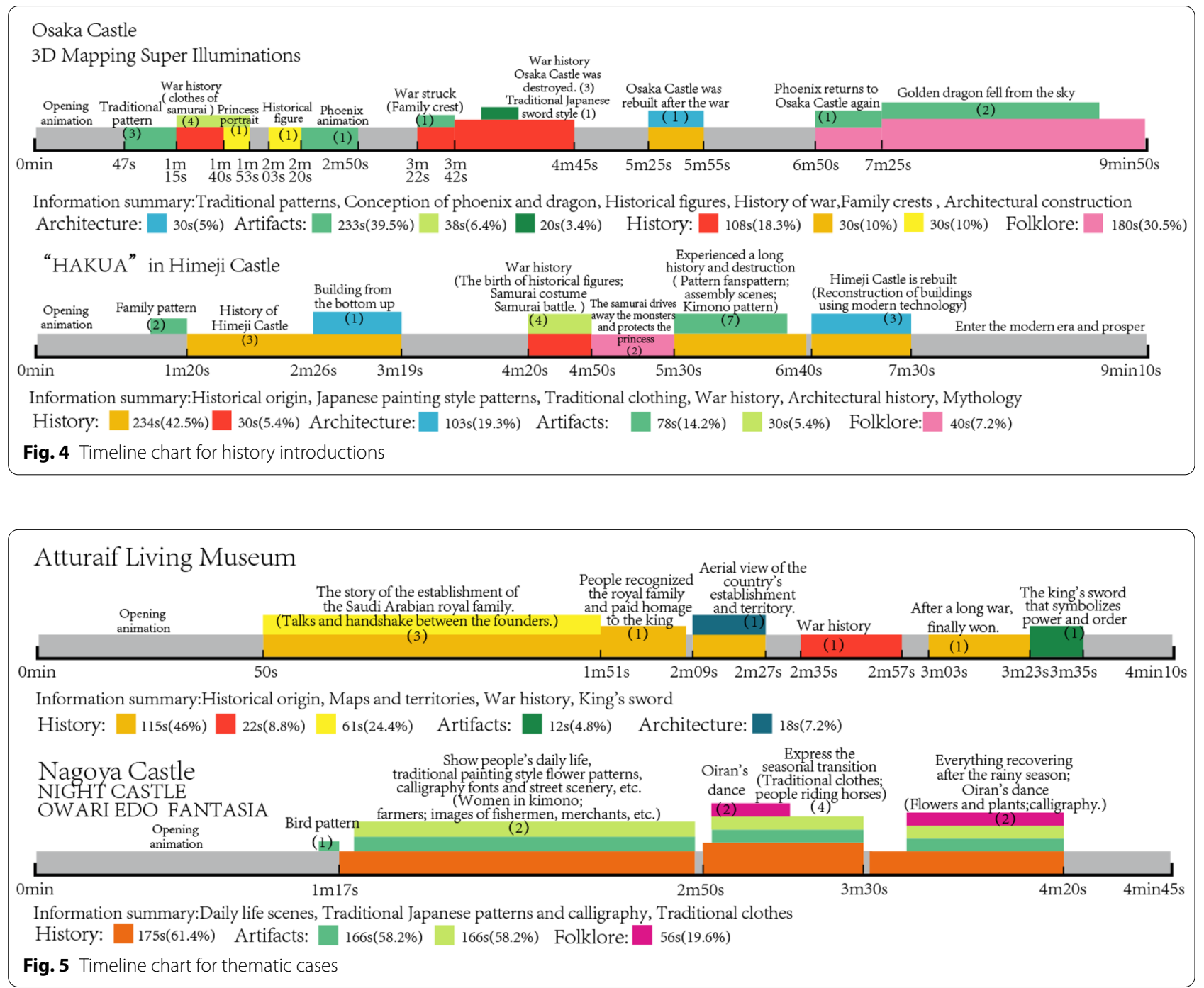

\section{Information tendency data analysis}

Based on the information characteristics and data from the building surface PJM, this study combined the two data sources in a comparative analysis to obtain the information tendency data (Fig. 9). In the figure, the information tendency is indicated by a polyline, and the transition nodes of information trends are marked by intersection points. Finally, this study calculates the difference between the data and marks these values above the corresponding data. Based on these data, the advantages and limitations of the two PJM types can be summarized and the causes analyzed for their differences. The following is an analysis and explanation of the data.

From the perspective of the overall number of scenes, more macro information related to traditional patterns, historical development, and architectural modeling can be observed in PJM. Correspondingly, micro information, such as mythology, folklore, and traditional cultural relics, are exhibited rarely.

The intersections marked in Fig. 9 represent the points where information trends change. From these intersection points, the scene unit numbers of medium-scale PJM begin to exceed the building surface PJM, and the primary data type to the right of the intersection is from the "independent stories and scenes" group (marked as triangles). Therefore, the information presented in medium-scale PJM can be considered to have a tendency to be "independent information." Conversely, the left side of the intersection mainly includes historical and architectural information, except for traditional art and costume information, which is concentrated in the "causal logic" group (marked as circles). According to the D-value data, the total number of scenes in this part of the building surface PJM is much higher than that for the medium-scale PJM. Therefore, it can be judged that the 


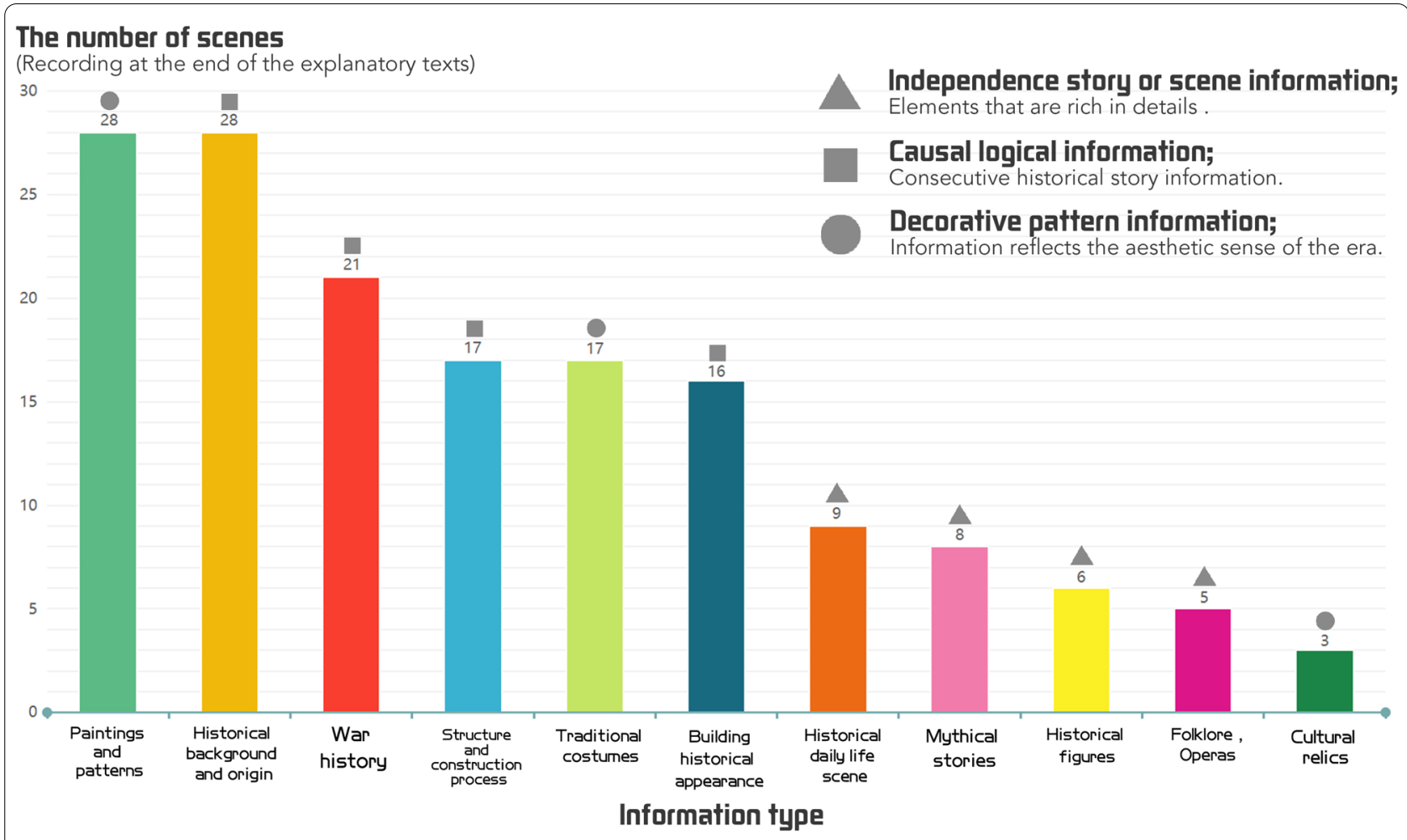

Fig. 6 Information characteristics of building surface PJM

information exhibited by the building surface PJM tends to be logical and continuous information.

Considering the gap in scene unit numbers, the information with the largest number of scene units is "paintings and patterns" with 58 scenes followed by "cultural relics" with 12 scenes and the least number of scene units is "folklore, operas" with 8 scenes. Chinese digital media designer and engineer Mr. Zongguo Chen commented on these data. He observed that PJM is a technology with excellent animation effects display capabilities, that is, it

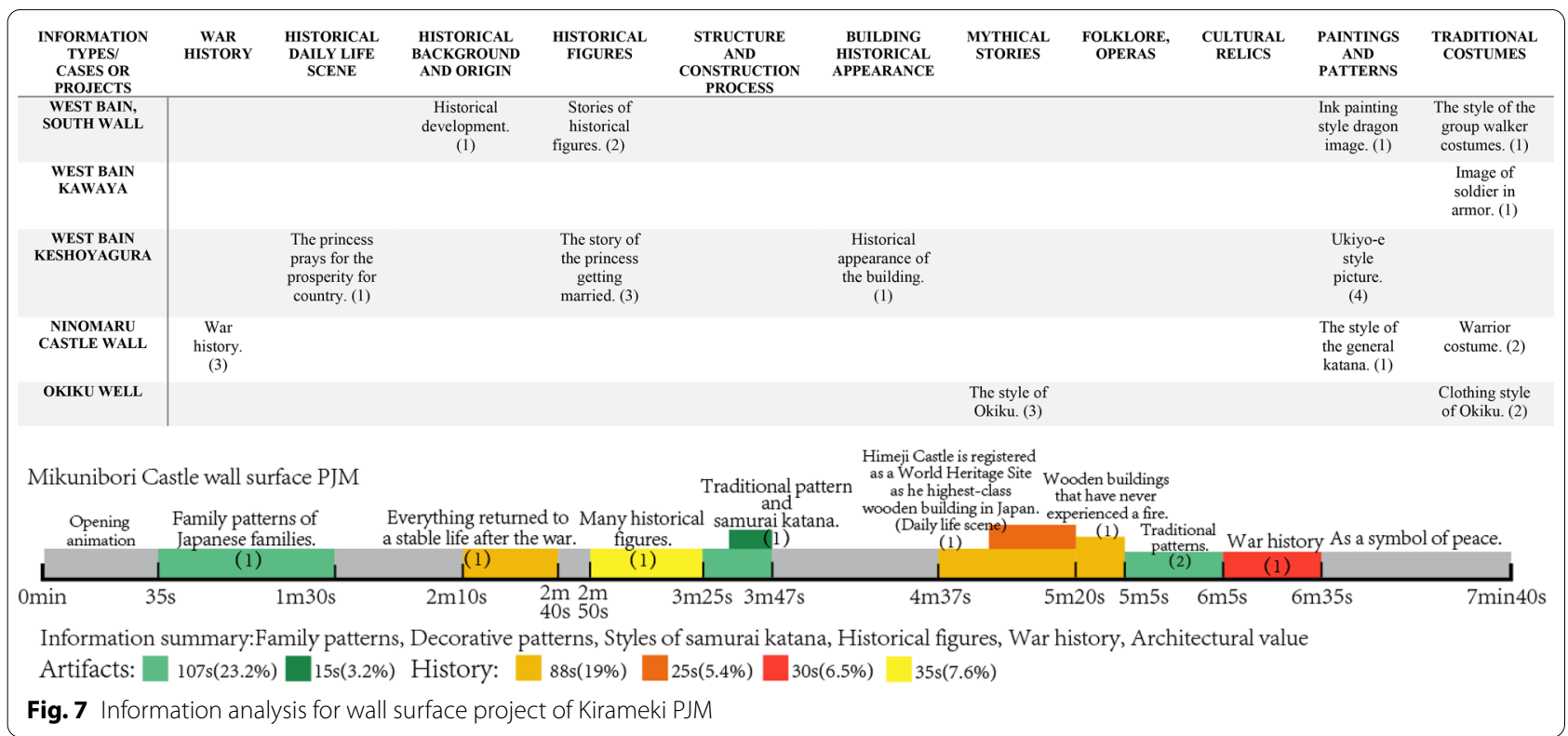


is essentially a design method for enriching visual effects. Therefore, it functions well at presenting painted and decorative pattern elements. If the PJM designer wants to present folk or opera content at a cultural heritage site, it is wiser to build a temporary stage and organize a theatrical performance because this type of information is more applicable to a live stage performance instead of a virtual projection. For instance, in the example of the Fantasy Festival of Light and Sound at Hirado Castle in 2018, the event was divided into three parts: a building surface PJM projection, an interactive holographic projection, and a live stage performance using real actors. There are still a few examples of folklore or opera demonstrated using PJM, such as the "Abo Dance" exhibited at the 2018 Kawa and Mori Light Art Festival in Tokushima Central Park, mostly because the related folklore has undergone a long history or excessive localization and only a few local residents learn and understand the specific contents of the PJM, which makes it difficult to create a live performance. Similarly, cultural relics that can be projected virtually better meet the needs for the appreciation of cultural relics compared with the appreciation of a physical exhibition of the relics at a museum [31]. However, the cultural relics exhibited using PJM are generally these relics that have been destroyed or cannot be physically exhibited for special reasons.

In summary, the small number of folklore or opera and cultural relics scene units is because the effect of virtual exhibitions of this type of information barely exceeds the effect of traditional methods for appreciating the exhibited materials [32]. Therefore, it is only necessary to use PJM under special circumstances where physical appreciation of the image, object, or site is impossible.

\section{Conclusion}

Through an analysis of 45 related examples of the application of PJM at cultural heritage sites around the world over the past 5 years, the results showed that only a few PJM events conducted at cultural heritage sites exhibited cultural content related to the target cultural heritage (35.6\%). Moreover, an in-depth analysis of 13 examples of cultural heritage sites summarized the specific contents, interaction possibilities, and related technologies. Based on this work to summarize the information tendency data, this study designed an original method for analyzing the PJM video contents, that is, an original timeline chart. According to the analysis of the projection information's characteristics and tendencies, the common features of building surface and medium-scale PJM were identified. Both PJM types have a good ability to express decorative and artistic elements, especially the display of patterns, paintings, and traditional costumes with cultural characteristics.
The features of building surface PJM include its excellence in presenting macro concepts, that is, continuous and cause-effect information, such as stories of historical development and war histories. The features of mediumscale PJM include its versatile ability to express many types of information with wide applicability. Compared with building surface PJM, the information expressed in medium-scale PJM has a tendency toward showing more "independent" information. Accordingly, medium-scale PJM has an excellent ability to express thematic contents, such as historical figures or historical daily life scenes.

Despite the large number of case studies, research, and verification that PJM functions well in the presentation of cultural information at world heritage sites, however, some cultural information cannot be presented using PJM "as a priority," such as cultural relics, folklore, or operas. Those cultural heritage contents were considered better applicable as live performances or museum exhibitions than as virtual projections. In particular, concerning opera or traditional dance, it is more judicious to build a temporary stage and organize a live performance instead of choosing PJM as an exhibition method. Accordingly, except when the PJM designer works to an innovative proposal, it is only necessary to use PJM under special circumstances where the physical appreciation of cultural heritage is impossible, such as when cultural relics have been destroyed or traditional skills lost.

Finally, three suggestions for the application of PJM at cultural heritage sites are proposed in this study, that is, considering the necessity of PJM at the cultural heritage site, the value of customized projection contents, and if PJM is possible or better than existing alternatives for presenting cultural heritage information.

First, the necessity of PJM at the cultural heritage site should be considered. The PJM contents exhibited at a cultural heritage site should be related to the cultural elements of the heritage site and have a certain degree of exclusivity. Accordingly, the value of cultural dissemination should be the first consideration.

Second, the projection contents should be determined according to the building sizes and available spaces at the target cultural heritage site. Based on the conclusions from the information tendency data, the size of the heritage building as a projection vehicle must influence the choice of PJM technology and contents. For instance, when the target heritage site is a castle, city wall, or gate building with a height of $15 \mathrm{~m}$ or more (see the heights of Osaka and Himeji castles, both over $45 \mathrm{~m}$ tall), building surface PJM could be selected as the main technology and information such as consecutive stories of historical development, building structures, and historical appearances can be chosen as the main PJM contents. Accordingly, when the target heritage building is a wall or theater 


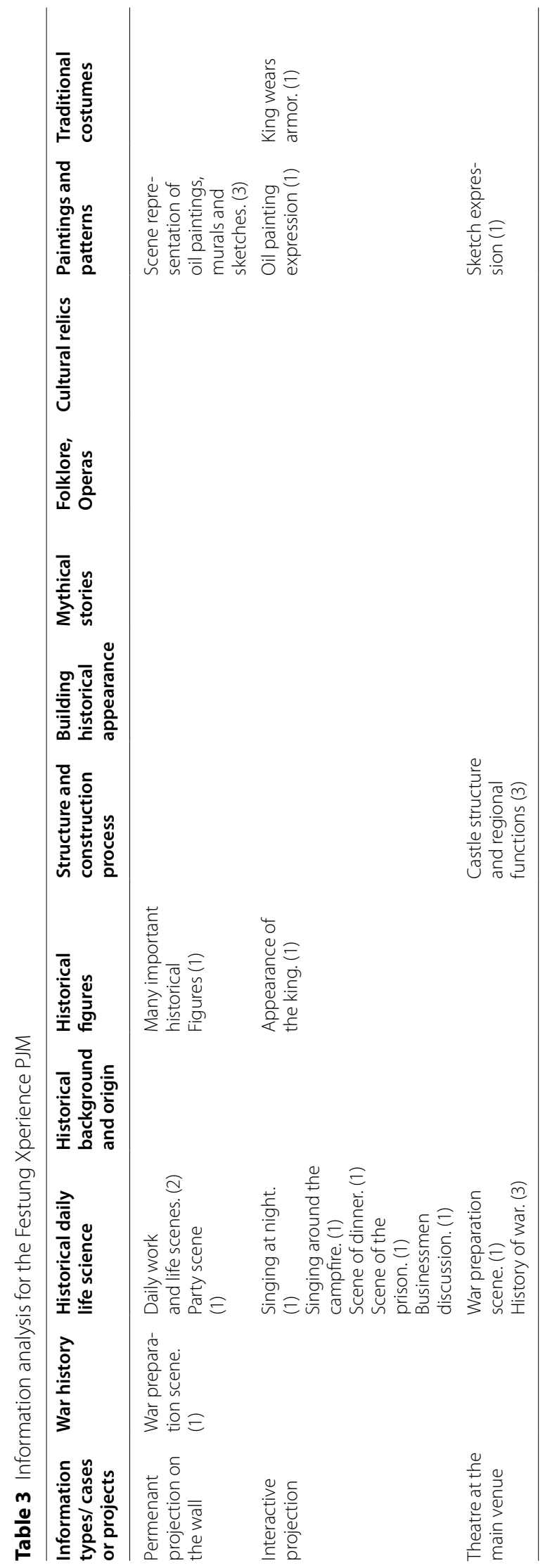



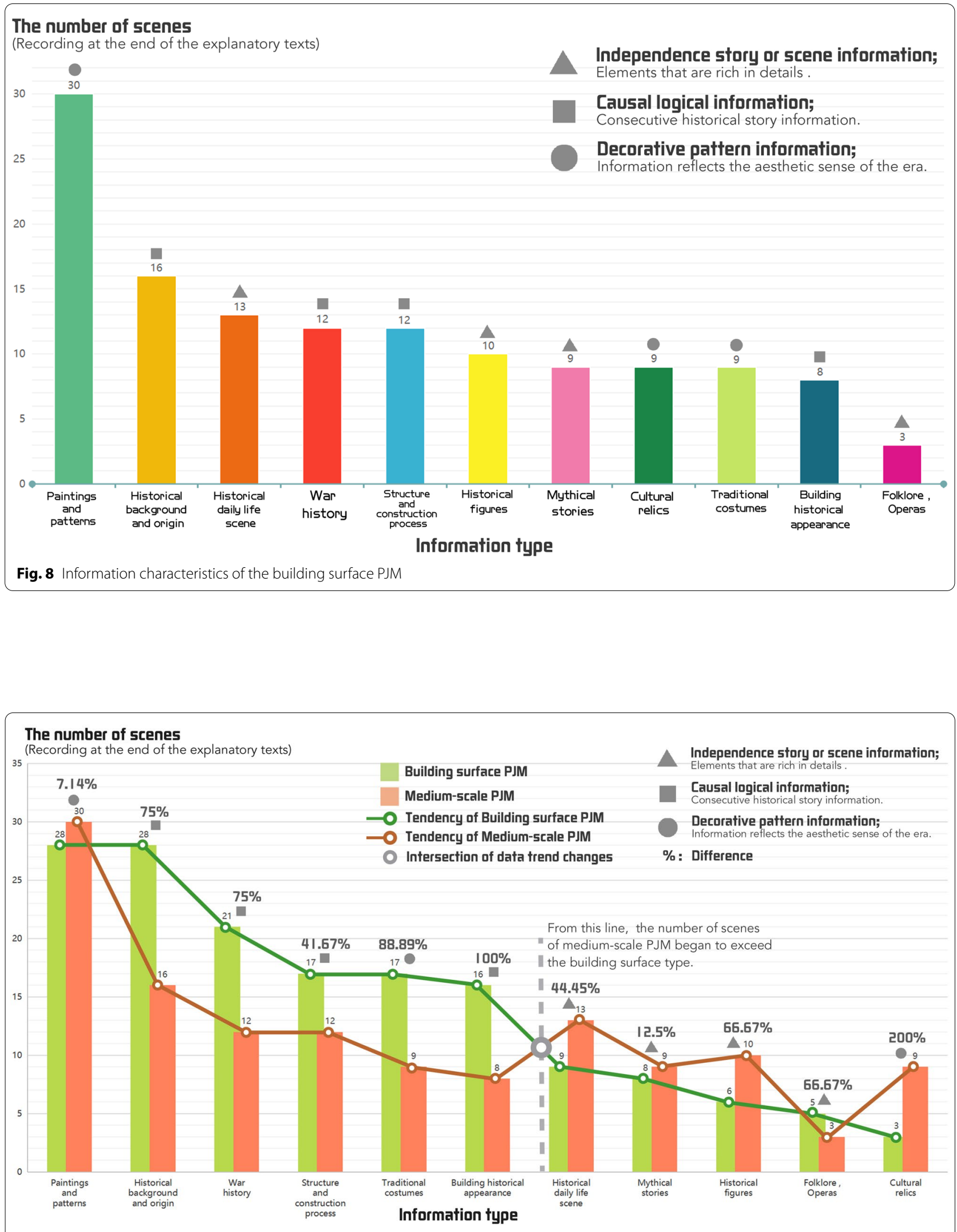

Fig. 9 Information tendency data 
with a height of about $4 \mathrm{~m}$ or more (see Dresden Fortress and Terra Sancta Museum as examples), medium-scale PJM, such as immersive PJM or holographic projection, could be the main choice and independent historical stories can be chosen as the PJM contents, such as descriptions of historical figures, historical daily life scenes, mythical stories, or virtual cultural relics.

If the designers want to showcase traditional dances, operas, and artifacts at a cultural heritage site, they should consider two issues in advance: whether the custom or cultural relic can only be exhibited by PJM because of loss or damage and whether PJM can show a better effect than a live theater performance. Therefore, if the target traditional dance and opera can still be performed on a live stage, building a real stage for theater performances will be the judicious choice. In addition, the PJM technology can be used to enrich the stage effects and provide an interactive experience if a stage performance presentation is chosen.

\section{Supplementary Information}

The online version contains supplementary material available at https://doi. org/10.1186/s40494-021-00579-0.

Additional file 1: Fig.S1. Data for building surface PJM examples. Fig. S2. Data for medium-scale PJM examples (long video). Table S3. Summary of relevant cases. Table S4. Data for medium-scale PJM examples.

\section{Acknowledgements}

The authors would like to express their sincere gratitude to Associate Professor Hiromu Ito from the University of Tsukuba for his guidance and constructive suggestions for this study. The authors are also very grateful to the Chinese digital media designers and engineers Mr. Zongguo Chen and Mr. Junbo Zhao for their advice and revisions of the study contents. We thank Peter Fogarty, MA English 1st Class, from Edanz (https://jp.edanz.com/ac), for editing a draft of this manuscript.

\section{Authors' contributions}

$\mathrm{HL}$ was responsible for completing the writing of this work, including the collection and investigation of cases, data analysis, and summary. HI was responsible for revising the logical framework of the paper and guiding and making suggestions on the methods for analyzing the example cases.

\section{Funding}

Funding was not received for this research.

\section{Availability of data and materials}

The datasets used and/or analyzed during the current study are available from the corresponding author on reasonable request.

\section{Declarations}

\section{Competing interests}

The authors declare that they have no competing interests.

Received: 7 June 2021 Accepted: 20 August 2021

Published online: 05 October 2021

\section{References}

1. Liu Y. Evaluating visitor experience of digital interpretation and presentation technologies at cultural heritage sites: a case study of the old town. Built Herit. 2020;4:1-4.

2. ICOMOS. The ICOMOS charter for the interpretation and presentation of cultural heritage sites. Quebec: ICOMOS International Scientific Committee on Interpretation and Presentation; 2008.

3. Ito $F$, Ito H, Take M. The way of participation of local people on the developing heritage management plan in Kumano pilgrimage route Iseji. Jpn Inst Landsc Archit. 2019;81(5):613-4 (in Japanese).

4. The Japanese Ministry of Land, Infrastructure, Transport and Tourism: projection mapping implementation manual (in Japanese). 2018. https:// www.mlit.go.jp/common/001228772.pdf.Accessed 01 Aug 2021.

5. Chen Y, Kelly G. Introduction: applying a landscape perspective to digital cultural heritage. Built Herit. 2020;4(2):1-4.

6. Caarls J, Jonker P, Kolstee Y, Rotteveel J, van Eck W. Augmented reality for art, design and cultural heritage-system design and evaluation. EURASIP J Image Video Process. 2009;2009:7-10.

7. Bostanci E, Kanwal N, Clark AF. Augmented reality applications for cultural heritage using Kinect. Hum Centric Comput Inf Sci. 2015;5(20):5-10.

8. Nofal E, Stevens R, Coomans T, Moere AV. Communicating the spatiotemporal transformation of architectural heritage via an in-situ projection mapping installation. Digit Appl Archaeol Cult Herit. 2018;11:2-5.

9. Shah ZQ, Anawar RR, Abd Yusof NF, Idris A. Development of usability framework for projection mapping to increase food dining experience. Int J Adv Trends Comput Sci Eng. 2020;9:3150-4.

10. Yoshikawa, K. Oya, K. Kimura, K. Kawashima, T. Mukaiyama, K. "Baidarka" Projection mapping: An exhibition practice to project video image directly to a cultural heritage (in Japanese). J Inst Image Inf Telev Eng Spec Featur 2016; 40: 296-297

11. Watanabe Y, Sueishi T, Ishikawa M. Development and prospects in projection mapping (Dynamic projection mapping) (in Japanese). J Inst Image Inf Telev Eng Spec Featur Proj Mapp Technol Appl. 2018;72:332-4.

12. Nicolopoulos S, Das PP, Bereciartua PJ, Karavasili F, Zacharias N, Pérez AG, Galanis AS, Rauch EF, Arenal R, Portillo J, Roqué-Rosell J. Novel characterization techniques for cultural heritage using a TEM orientation imaging in combination with 3D precession diffraction tomography: a case study of green and white ancient Roman glass tesserae. Herit Sci. 2018;6(1):1-12.

13. Guo Y, Chu SC, Liu Z, Qiu C, Luo H, Tan J. A real-time interactive system of surface reconstruction and dynamic projection mapping with RGB-depth sensor and projector. Int J Distrib Sens Netw. 2018;14(7):3-5.

14. Mizuno $S$. Interactive projection mapping using traditional Japanese houses (in Japanese). Inf Process Soc Jpn J Digit Content. 2019;7(1):22-32.

15. Chris L. digital cultural heritage: FUTURE VISIONS, a landscape perspective. Int Conf Rep Built Herit. 2020;4(7):2-4.

16. Playlist named "PJM" in YouTube. https://www.youtube.com/channel/ UCtlOwB037KZpxkVstjOFFUQ/playlists. Accessed 03 Apr 2021.

17. Mukaiyama K, Kobayashi M. A Projection Mapping of Cultural Heritages, Its Exhibition and Evaluation (in Japanese). J Inst Image Inf Telev Eng Tech Rep. 2015;39:296-7.

18. Izuhara, R. Fuji, A. Maeda, Y. Experimental research of projection mapping for "Tsudumi-mon" in Kanazawa Sta. towards a bridge between people and town with ICT (in Japanese). Bull JSSD 2014; 1-2

19. Mao, S. Application research of "Digital Landscape" in the environmental design of residential areas (in Chinese). Hunan Normal University. 2012. p.13-21

20. Portfolio of Tokyo Team lab. https://www.teamlab.art/zh-hans/. Accessed 20 Feb 2021.

21. AV Magazine. Cathedral projection mapping marks UNESCO recognition 2018. https://www.avinteractive.com/news/projection/cathedral-proje ction-mapping-marks-unesco-recognition-12-11-2018. Accessed 20 Feb 2021.

22. YouTube channel of Night Movie Channel of Osaka Japan. Osaka Castle 3D mapping super illumination Japan 2014 2015. https://www.youtube. $\mathrm{com} /$ watch?v=5HebN8OFhak\&list=PLcKMIXRGS8yQiGOU4Wn5JoqluF23xs4B\&index=43. Accessed 14 Apr 2021.

23. YouTube channel of Takashi Matsuo. Himeji Castle 3D projection mapping 2015.https://www.youtube.com/watch? $v=x O 3 b 6 \mathrm{m6ib6c \& list=}$ PLcK MIXRGS8yQiGOU4Wn5Joqlu-F23xs4B\&index=43. Accessed 14 Apr 2021. 
24. YouTube channel of FIREWORKSVIEWERS. NAKED NIGHT CASTLE OWAR EDO FANTASIA 2018. https://www.youtube.com/watch?v=pRcZaQ4F2z w\&list $=$ PLCKMIXRGS8yQiGOU4Wn5Joqlu-F23xs4B\&index=59. Accessed 03 Apr 2021.

25. TAMSCHICK MEDIA+SPACE. Atturaif Living Museum 2019. https://www tamschick.com/projekte/atturaif-the-living-museum/. Accessed 03 Dec 2020.

26. Work of Moment Factory. AURA AT THE NOTRE-DAME BASILICA 2017. https://momentfactory.com/work/all/all/aura. Accessed 06 Nov 2020

27. Portfolio of the projection mapping company Maxin10sity. https://www. maxin10sity.net/portfolionew. Accessed 25 Feb 2021.

28. Work of NAKED. https://naked.co.jp/en/works. Accessed 03 Dec 2020

29. YouTube channel of SYMUNITY GROUP. KIRAMEKI 2017. https://www. youtube.com/watch? $\mathrm{v}=\mathrm{g}-\mathrm{mHrANjMwA \& list=PLCKMIXRGS8yQiGOU} 4 \mathrm{Wn}$ 5Joqlu-F23xs4B\&index=36. Accessed 03 Apr 2021.
30. TAMSCHICK MEDIA+SPACE. Festung Xperience 2019. https://www.tamsC hick.com/projekte/festung-xperience/. Accessed 03 Dec 2020.

31. Ana T. Modern built heritage conservation policies: how to keep authenticity and emotion in the age of digital culture. Built Herit. 2018;2:17-9.

32. De Rojas C, Carmen C. Visitors' experience, mood and satisfaction in a heritage context: evidence from an interpretation center. Tour Manage. 2008;29(3):525-8.

\section{Publisher's Note}

Springer Nature remains neutral with regard to jurisdictional claims in published maps and institutional affiliations.

\section{Submit your manuscript to a SpringerOpen ${ }^{\odot}$ journal and benefit from:}

- Convenient online submission

- Rigorous peer review

- Open access: articles freely available online

- High visibility within the field

- Retaining the copyright to your article

Submit your next manuscript at $\gg$ springeropen.com 